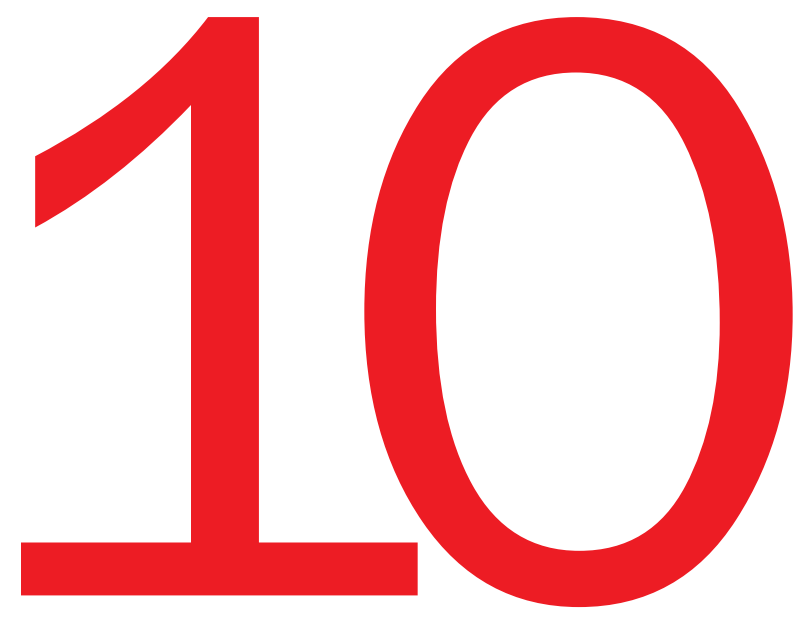

\title{
Abstract
}

While it is generally recognized that nurses and nursing issues are underrepresented in the media, the contrary is also true during major public health care crises like Ebola and SARS (Severe Acute Respiratory Syndrome). We see this phenomenon unfolding in the midst of the current COVID-19 pandemic with nurses and nursing issues receiving extensive media coverage in Canada and internationally. To gain more insights into this media coverage, we analyzed the content of Canadian news stories published in both English and French during the first five months of the COVID-19 pandemic. This paper presents the findings of our analysis and identifies important lessons learned. We believe that our findings serve as an important starting point for understanding nurses' agency and the media savviness they displayed during the first months of the pandemic.

Key words Canada, content analysis, COVID-19, media, nurses, nursing

\section{Nursing Voices during COVID-19: An Analysis of Canadian Media Coverage}

\author{
MARILOU GAGNON \& AMÉLIE PERRON
}

\section{Introduction}

The representation of nurses and nursing issues in the media has been a topic of interest for many decades now. In 1997, the Woodhull Study on Nursing in the Media found that nurses were largely underrepresented in the health news media, accounting for only $4 \%$ of the sources cited in news stories.[1] When Mason and colleagues replicated the Woodhull study twenty years later, they concluded that representation had actually decreased over time, from $4 \%$ to $2 \%$.[2] When they interviewed journalists to understand this phenomenon, they identified a number of factors including that nurses and the nursing profession more generally are not strategic in their use of and engagement with media.[3] They also noted that employers have been known to prevent nurses from talking to the media by including non-disparagement clauses or mediaspecific clauses in work contracts, by implementing topdown media policies that require a multi-step slow process of approval by senior management, and by punishing nurses who speak to media thereby creating a culture of fear and silence.[3]

While it is generally agreed that nurses and nursing issues continue to be underrepresented in the media, the contrary is also true during major public health care crises such as Ebola and SARS (Severe Acute Respiratory Syndrome).[4-5] We see this phenomenon unfolding in the midst the current COVID-19 pandemic with nurses and nursing issues receiving extensive media coverage in Canada and internationally. In order to gain more insights into this media coverage, we analyzed the content of Canadian news stories published in both English and French during the first five months of the COVID-19 pandemic. Unlike previous media analyses which tend to 


\begin{tabular}{|l|l|l|}
\hline \multicolumn{2}{|c|}{ Table 1: Sample } \\
\hline $\begin{array}{l}\text { Country } \\
\text { Dates }\end{array}$ & $\begin{array}{l}\text { Canada } \\
\text { January } 12020 \text { to May 21 2020 }\end{array}$ \\
\hline English & Whistleblowing (or Whistleblower) AND nurses AND COVID & 3 \\
English & Speaking out AND nurses AND COVID & 19 \\
English & Reporting AND nurses AND COVID & 3 \\
English & Denounce AND nurses AND COVID & 4 \\
English & Nurses AND COVID & 9 \\
\hline French & & 38 (total) \\
French & Dénonce ET infirmières ET COVID & 13 \\
French & Dénonciation ET infirmières ET COVID & 2 \\
French & Sonne l'alarme ET infirmières ET COVID & 2 \\
French & Signale ET infirmières ET COVID & 8 \\
French & Lanceur d'alerte ET infirmières ET COVID & 1 \\
French & Omerta ET infirmières ET COVID & 4 \\
French & Cri du cœur ET infirmières ET COVID & 2 \\
\hline & Infirmières ET COVID & 13 \\
\hline
\end{tabular}

focus on media's representations of nurses and nursing issues (e.g., workplace violence, salaries, shortage),[4-8] we were particularly interested in analyzing the voice of nurses - both collective and individual. As such, we aimed to take a closer look at Canadian nurses' use of media for sharing their experiences, raising concerns, speaking up, blowing the whistle, and advocating for themselves and their clients during COVID-19. We believe that our findings serve as an important starting point for understanding nurses' agency and the media savviness they displayed during the first few months of the pandemic.

\section{Methods}

To conduct a rapid and rigorous analysis of news coverage, we opted to use qualitative content analysis. Qualitative content analysis was born out of quantitative content analysis, a method developed in the first half of the twentieth century to analyze large amounts of textual data (primarily from media) to capture the frequency of ideas and concepts. $[9,10]$ The goal of qualitative content analysis is different, in that it seeks to describe the actual content of the data and offers new insights into the unit of analysis.[9,10] We completed our search using the Google Advanced Search operator, which offers the options of using and combining keywords, as well as limiting the search to a specific country and specific dates. We used five key word combinations to search the English media coverage and eight key word combinations to search the French media coverage. We also limited the search to Canada and news stories published between January 1 and May 21 2020. After reviewing our initial sample of 119 news stories and eliminating duplicates, stories unrelated to COVID-19 or stories that did not include a collective or individual nursing voice, we had a final sample of 83 news stories. See Table 1. Each story was analyzed using a series of questions: Who is speaking? Are they speaking as a nursing collective (e.g., union, association, regulatory body) or as individual nurses? Are individual nurses anonymized or identified (e.g., full name with or without picture)? What is being said in the news stories? What is the essence of the message? How is the message changing over time? Content extracted from this first round of high-level analysis was then subjected to another, more indepth, round of inductive analysis to identify common themes.

\section{Results}

\section{Overview of the media coverage}

Of the 83 news stories, 38 (46\%) were published in English and 45 (54\%) in French. The totality of the stories published in French were based in the province of Quebec. Of the stories published in English, 4 were national in scope, 15 were based in Ontario, 10 in Quebec, 5 in British Columbia, 1 in Newfoundland, 1 in Saskatchewan, 1 in Alberta, and 1 in Nova Scotia. Of the total sample, $66 \%$ of the news coverage featured the collective or individual voices of nurses located in Quebec. A number of factors may have contributed to this extensive media coverage including: 
-Quebec has been and continues to be at the centre of the COVID-19 pandemic in Canada with a total of 55,079 cases and 5,448 deaths (as of June 27 2020).

-Like other provinces, Quebec declared a public health emergency in March but unlike other provinces, it issued a ministerial order (2020-007) that amended collective agreements and imposed changes to schedules, leaves, vacations, staff mobility, etc.

-On March 30 2020, the Fédération inteprofessionnelle de la santé du Québec (FIQ) launched the online platform "Je dénonce " to encourage nurses and other health care providers as well as members of the public to report dangerous or unacceptable situations during the COVID-19 pandemic.

-On May 16 2020, the Quebec government launched a new email inbox "On vous écoute" to encourage health care providers to report issues and problematic practices in their workplaces during the COVID-19 pandemic.

-Over the past 2 and half years, the province has seen an unprecedented wave of public denunciations by nurses (e.g., sit-ins, media, social media, public forums, protests ) - a phenomenon that is currently under study .

To answer the question "Who is speaking?" we determined whether new stories featured nurses speaking as a collective (e.g., union, association, regulatory body) or as individuals or both. It was common for both collective and individual voices to be featured in the same news story. As such, to simplify the presentation of the findings, we opted to count the number of instances where a collective voice was featured and did the same for individual voices. Collective voices, largely union voices, appeared 52 times in our sample. The union voices most featured in the media stories were those of the Fédération inteprofessionnelle de la santé du Québec (FIQ) $(n=26$ or $57 \%$ ), the Canadian Federation of Nurses Unions (CFNU) ( $n=5$ or $11 \%$ ), Ontario Nurses Association (ONA) (3 or $7 \%)$, and the British Columbia Nurses' Union (BCNU) $(n=3$ or $7 \%)$.

Individual voices of nurses appeared in news stories 44 times. We found equal numbers of stories in which nurses were identified $(n=20)$ and anonymized $(n=20)$, as well as 4 stories where some nurses were identified and some were not. The main reason cited for anonymizing was the risk of retaliation in the workplace and sanctions for speaking out in the media (including job loss).

\section{A deeper dive into the content}

During the second round of analysis, we identified one common thread centered on the COVID-19 pandemic as seen through the war metaphor. This was supplemented by four common themes. See Figure 1. The first theme, "Answering the call", captured the early days of the COVID-19 pandemic when stories focused largely on nurses who were called on to volunteer, come out of retirement, graduate early, take on new positions, redeploy in new settings, and so forth. Emphasis was placed on the soldier-like characteristics of a "good nurse" portrayed as always ready, willing, and able to answer the call to duty in the face of the unknown. However, as COVID-19 began to

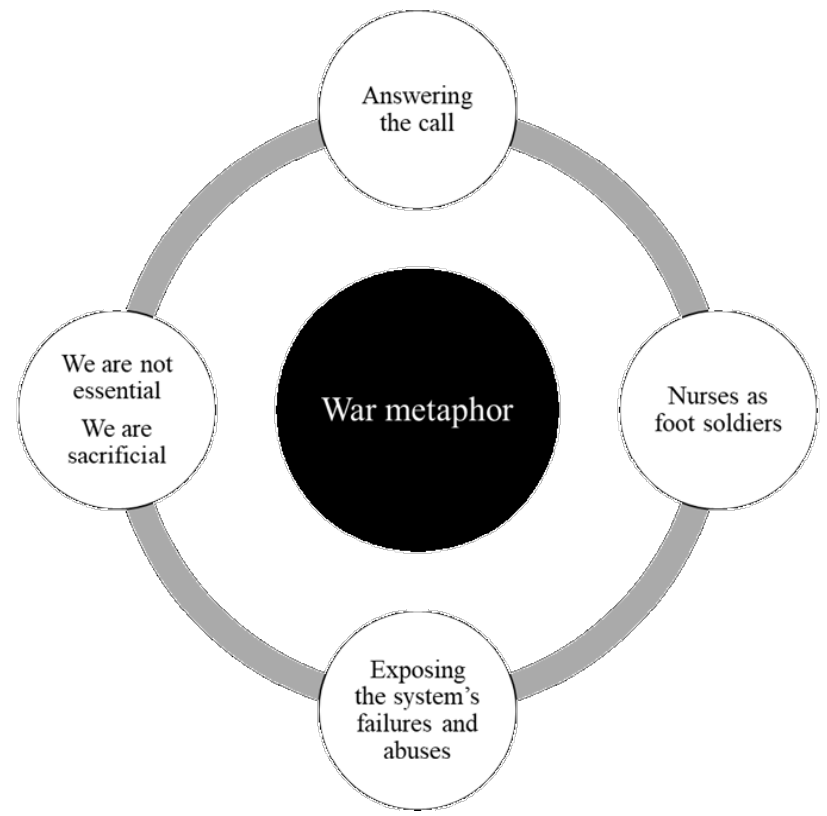

Figure 1: Themes 
spread, it became evident that nurses were being sent to war without the proper equipment (or no equipment at all), without enough information, without sufficient human and physical resources, and without enough support and compensation (e.g., food and childcare stipends, risk premiums, paid sick days). This is where our second theme comes in: "Nurses as foot soldiers". Most of the news stories from the end of March to mid-May 2020 featured detailed accounts of the harsh reality of nurses at the frontline (described as a 'war zone' by many nurses), which we summarized using five sub-themes:

1.Not having access to proper personal protective equipment due to shortage, severe rationing and/or recycling of equipment including uniforms, masks, face shields, gowns, etc.;

2.Being forced to work despite health risks (e.g. pregnancy, immunocompromised state, chronic respiratory illness) and/or COVID-19 symptoms and/or unsafe work conditions (including unsafe nurse-client ratios);

3.Witnessing the unbearable - from clients getting sick and dying, often in deplorable conditions, to seeing colleagues "drop like flies" due to systemic negligence;

4.Dealing with the physical impact of contracting COVID-19 and the psychological impact of working in a broken and illprepared system (e.g., stress, anxiety, burnout, PTSD)

5.Not being able to adhere to best practices to prevent the spread of COVID-19, to provide quality and safe care, and to protect oneself and others.

The third theme, "Exposing the system's failures and abuses", emerged from media stories covering troubling testimonials by individual nurses. In Quebec in particular, these included two high profile testimonials by nurses Nadia Lambert and Kristy-Lyn Kemp, as well as a large number of publicly available testimonials posted on the FIQ's online platform "Je dénonce ". Through these testimonials, we learned that COVID-19 had exacerbated long-standing issues in the health care system (e.g., shortage, unsafe nurse-client ratios, staff mobility, poor communication, etc.) and intensified dangerous practices such as mandatory overtime.[11] Testimonials posted on "Je dénonce " also revealed abuses ranging from being locked in at work by managers to being muzzled and threatened by employers. Finally, the fourth theme was inspired by an opinion piece published in The New York Times on May 52020 entitled "We are not essential. We are sacrificial". This piece, written by Metropolitan Transportation Authority conductor Sujatha Gidla, perfectly captures how Canadian nurses talked about the position they occupied within the health care system as disposable workers, the way they were treated by governments and health care institutions as foot soldiers, and how their health and their lives were seen as collateral damage in the "war" against COVID-19. This led to many nurses being quoted in the media as saying: "I didn't sign up to die on my job".

\section{Discussion}

Our findings are consistent with previous media analyses conducted by Canadian scholar McGillis Hall and colleagues after the Ebola and SARS epidemics (4-5). They too found that media often portrayed major public health care crises through the war metaphor and nurses as "war heroes" (4-5). In our sample, we noted that nurses themselves drew on this imagery to describe their experiences and convey how they felt, the hardships they faced, the way they were treated and impacted, the physical and emotional cost of these stressful experiences. Though nurses endorsed the hero identity in the earlier weeks of the pandemic, which was continuously reinforced across the country by media, nursing organizations, governments, health leaders and the public, they overwhelmingly came to reject it. They "did not feel like heroes" as many expressed in news stories. In an opinion piece published on April 24 2020 in Le Devoir, Martin and colleagues argued that nurses should be extremely critical of recognition that only serves the interests of the state and not of the workers themselves. Many nurses who pushed back against the hero narrative adopted this critical disposition.

Our analysis differed from previously conducted media analyses in that it focused explicitly on the voices of nurses providing direct patient care. In order words, it focused on nurses talking as opposed to media talking about nurses. The difference here is important. The media coverage in the first few months of COVID-19 was unusual because it featured news stories in which nurses were using agency, power, and savviness to convey what they believed to be important, lacking, needed, etc. These stories also stemmed from skillful use of social media (especially Facebook) and online platforms, including "Je dénonce ". For example, the highprofile testimonial of nurse Nadia Lambert was initially posted on Facebook and shared 20,000 times in 24 hours which led to media covering her story. Along the same lines, the launch of the online platform "Je dénonce" gave media ready access to hundreds of testimonials, which in turn, increased media coverage centered on the voices of nurses - and amplified by the collective voice of the FIQ.

The FIQ was a strong collective voice across our sample, representing $57 \%$ of the union voices featured in the Canadian 
news coverage. As part of our work on whistleblowing in nursing, we have previously discussed the importance of exploring the role of nursing unions in facilitating disclosure of wrongdoing.[12] The same can be said about the role of unions in facilitating anonymous and large-scale reporting of dangerous or unacceptable situations during major public health care crises - as well as amplifying the voices of their members. This role is not discussed in the current literature despite the need to find ways of increasing the representation of nurses in the media. Too often, the aim of nursing scholars and organization is to position nurses as health experts in the media, yet similar if not greater attention should be devoted to normalizing and increasing nurses' use of media as a tool for advocacy and political action. This could be achieved by providing nurses with media training while also educating reporters on the benefits of including nurses as key sources for news stories. This would encourage nurses to use the media to speak out and make demands, as a tool for change and as a strategy to preserve the public interest.

\section{Conclusion}

Our analysis offers additional insights to understand nurses' agency and their media savviness during the first few months of the COVID-19 pandemic. Our analysis leads us to conclude that, while the recognition of nurses as health experts by the media is beneficial, what nurses need more is the freedom to speak, the amplifying capacity of a strong collective voice, and the power of media and technology, including social media, to influence public debates and health policy. COVID-19 has shown us that when nurses speak, the media listens.

\section{References}

1.Sigma Theta Tau International. The Woodhull study on nursing and the media: Health care's invisible partner. 1997. Available from URL: https://sigma.nursingrepository.org/ handle/10755/624124. Accessed June 292020.

2.Mason DJ, Nixon L, Glickstein B, Han S, Westphaln K, Carter L. The Woodhull Study Revisited: Nurses' Representation on in Health News Media 20 Years Later. Journal of Nursing Scholarship. 2018;50(6): 695-704.

3.Mason DJ, Glickstein B, Westphaln K. Journalists' Experiences with Using Nurses as Sources. American Journal of Nursing. 2018;118(10): 42-50.

4.McGillis L, Angus J, Peter E, O'Brien-Pallas, L, Wynn, F, Donner G. Media Portrayal of Nurses' Perspectives and Concerns in the SARS Crisis in Toronto. Journal of Nursing Scholarship. 2003;35(3):211-216.
5.McGillis L, Kashin J. Public Understanding of the Role of Nurses During Ebola. Journal of Nursing Scholarship. 2016;48(1):91-97.

6.Blomberg H, Stier J. Metaphorical expressions used in Swedish news media narratives to portray the shortage of nurses and their working conditions. Journal of Advanced Nursing. 2015;72(2):382-395.

7.Hoyle LP, Smith E, Mahoney C, Kyle RG. Media Depictions of "Unacceptable” Workplace Violence Toward Nurses. Policy, Politics \& Nursing Practice. 2018;19(3-4):57-71.

8.Urban A-M. Textually mediated discourses in Canadian news stories: Situating nurses' salaries as the problem. Nursing Inquiry. 2018;25:e12233.

9.Hsiu-Hsieh H-F, Shannon SE. Three Approaches to Qualitative Content Analysis. Qualitative Health Research. 2005;15(9):1277-1288.

10.Schreier M. Qualitative Content Analysis. In: U. Flick (Ed), The Sage Handbook of Qualitative Data Analysis. London: Sage, 2014; 170-183.

11.Perron A, Dufour C, Marcogliese E, Gagnon M. La dénonciation infirmière en contexte de pandémie de COVID-19: une analyse de contenu de la plate-forme "Je dénonce ". Aporia : La revue en sciences infirmières. (Under Review)

12.Gagnon M, Perron, A. Whistleblowing: A concept analysis. Nursing and Health Sciences. 2020;22:381-389.

To contact the authors:

Marilou Gagnon

Associate Professor

School of Nursing

University of Victoria

2300 McKenzie Ave

Victoria, BC, Canada

V8N $5 M 8$

email: marilougagnon@uvic.ca

Amélie Perron

Associate Professor

University of Ottawa

Faculty of Health Sciences

School of Nursing 